\title{
INFORMATION SYSTEMS OUTSOURCING RELATIONSHIP MODEL
}

\author{
Richard Fleming \\ School of Information Systems, Technology and Management \\ The University of New South Wales, Sydney, Australia \\ Graham Low \\ School of Information Systems, Technology and Management \\ The University of New South Wales, Sydney, Australia \\ Email: g.low@unsw.edu.au
}

\begin{abstract}
Increasing attention is being paid to what determines the success of an information systems outsourcing arrangement. The current research aims to provide an improved understanding of the factors influencing the outcome of an information systems outsourcing relationship and to provide a preliminary validation of an extended outsourcing relationship model by interviews with information systems outsourcing professionals in both the client and vendor of a major Australian outsourcing relationship. It also investigates whether the client and the vendor perceive the relationship differently and if so, how they perceive it differently and whether the two perspectives are interrelated.

Keywords: outsourcing models, outsourcing relationships, outsourcing factors
\end{abstract}

\section{INTRODUCTION}

The relationship between client and vendor is a vital component of a successful outsourcing agreement (Kern, 1997, Kern and Willcocks, 2000, Koh et al., 2004, Kishore et al., 2003, McFarlan and Nolan, 1995). Social exchange theory sees the relationship as involving teamwork between the parties to achieve a win-win situation (Kern, 1997, Kern and Willcocks, 2000) while contract theory sees it as a formal agreement between the parties for the exchange of goods and services (Fitzgerald and Willcocks, 1994, Kern, 1997, Kern and Willcocks, 2000).

The approach taken by outsourcing partners in establishing a relationship affects its longterm management. If the relationship is developed from a social exchange theory perspective (soft-based management), it is established to respond dynamically to new requirements from either partner (Kern, 1997). If the relationship is developed and managed from a contract theory perspective (hard-based management), it remains simple and easily 
controlled. The negative to this approach is that it can be too rigid and unyielding for the partners to manage successfully (Kern, 1997).

A successful relationship requires a combination of soft-based and hard-based relationship management. Hard-based relationship management allows a relationship to be established within a strong contractual framework to govern the ensuing soft-based relationship (Fitzgerald and Willcocks, 1994, Kern, 1997, Kern and Willcocks, 2000, Koh et al., 2004). A relationship that combines the legal contract with mutual trust allows for a much stronger bond between the client and vendor parties (Klepper, 1994, Lee and Kim, 2005, Sabherwal, 1999). The latter forms an effective partnership and plays a major role in creating a successful outsourcing agreement (Lee and Kim, 2005).

Dibbern et al. (2004) indicated the need for further research into how the client and vendor interact within a relationship in their review of the information systems outsourcing literature. The current research aims to provide an improved understanding of the factors influencing the outcome of an information systems outsourcing relationship and to provide a preliminary validation of an extended information systems outsourcing relationship model within an Australian context. It also investigates whether the client and the vendor perceive the relationship differently and if so, how they perceive it differently and whether the two perspectives are interrelated.

The paper is organised as follows: We review the relevant literature and then outline the research approach. This is followed by the development of the extended outsourcing relationship model, followed by a preliminary validation and conclusions.

\section{PREVIOUS OUTSOURCING RELATIONSHIP MODELS}

Information systems outsourcing relationship models have been designed to measure and provide an understanding of which aspects of a soft-based outsourcing relationship lead to outsourcing success for both the client and the vendor. Within these models the determinant variables of outsourcing success can be categorised as behavioural partnership variables and psychological partnership variables. The former are the key factors that affect the operational performance of the relationship while the latter are the degree to which the parties believe that the partnership will be sustained over time (Henderson, 1990, Lee and Kim, 2005).

We review five outsourcing relationship models (Henderson (1990), Lee and Kim (1999, , 2005), Kim and Chung (2003) and Kim and Park (2003)) prior to proposing an extended outsourcing relationship model.

Henderson's (1990) model distinguished between performance (behavioural) and psychological variables (Figure 1). The behavioural variables were referred to as "partnership in action" while the psychological variables were referred to as "partnership in context". He developed the model through interviews with senior executives together with a follow-up workshop. 


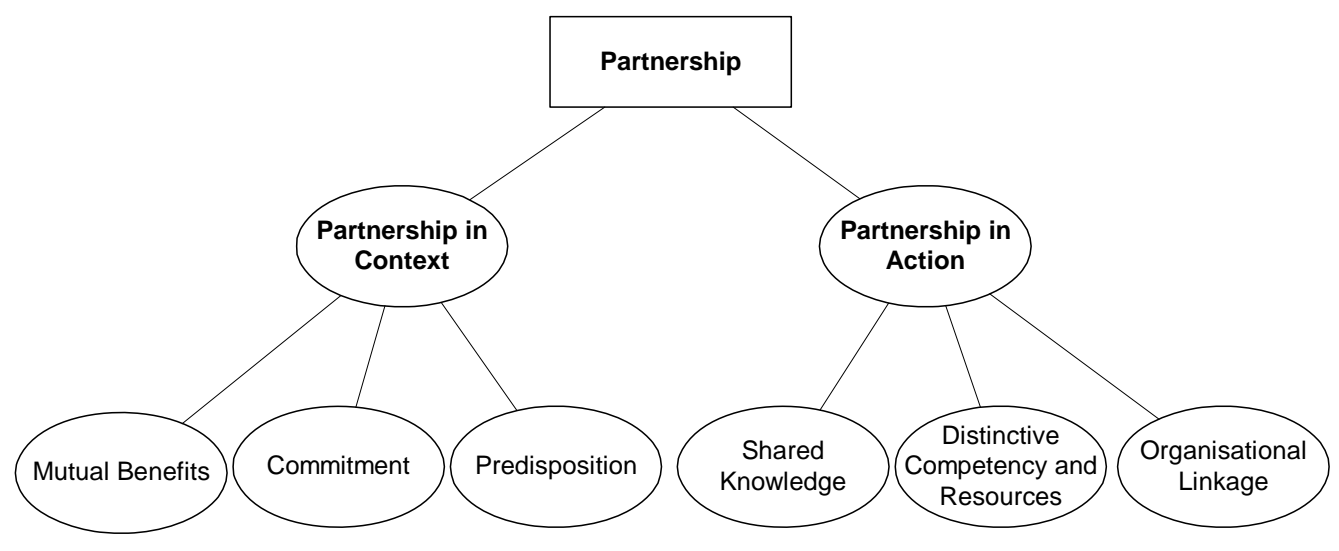

Figure 3 - Henderson (1990) partnership model

Lee and Kim (1999) distinguished between "determinants of partnership quality” and "partnership quality" (Figure 2). The former is a behavioural dimension that directly influences the psychological dimension (“partnership quality” between the client and vendor).

\section{Determinants of Partnership Quality}

\section{(Behavioural Dimension)}

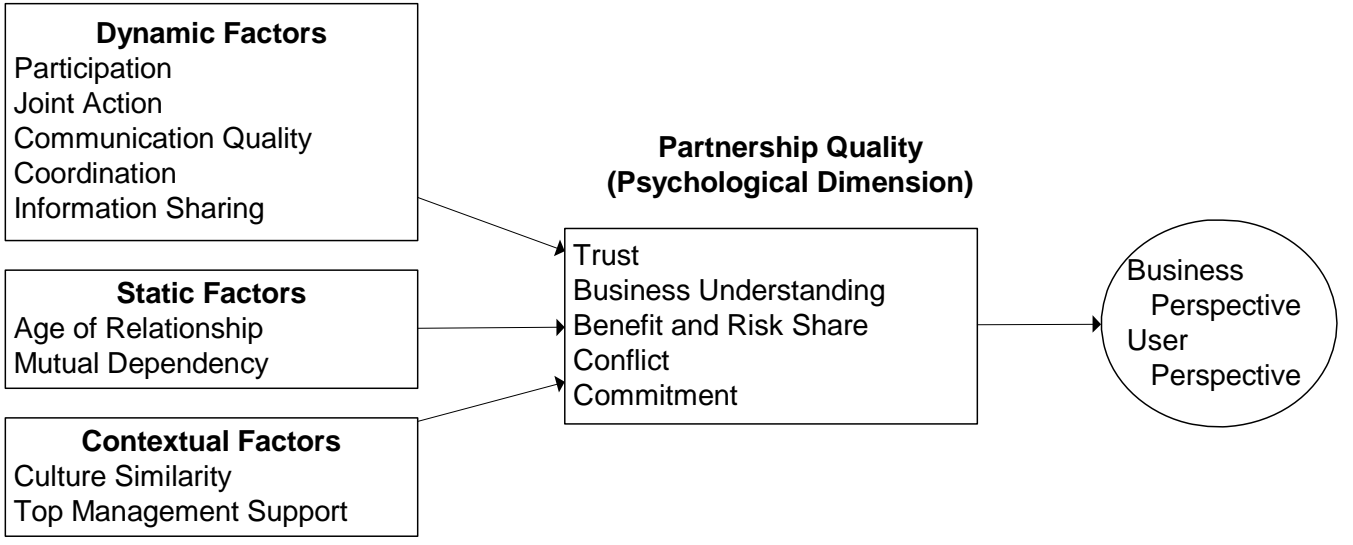

Figure 2 - Lee and Kim (1999) Research model for partnership quality

Although the Lee and Kim (1999) model was statistically significant, Lee (2005) recognised it "followed intuition rather than any theories" as the model "could not suggest a strong theoretical background for a 3-stage model (antecedents-process-outcome)”. This led Lee and Kim (2005) to develop and test three different theoretically supported models based on similar variables and dimensions. The three models were direct modifications of the Henderson (1990) model.

- $\quad$ Model Based on Behavioural-Attitudinal Theory -

- Figure 3 (2-dimensional model with the set of behavioural variables influencing psychological variables). 
- Simple Direct Path Model (1-dimensional model with all variables directly influencing outsourcing success).

- Model Based on a Theory of Reasoned Action (2-dimensional model with the set of psychological variables influencing behavioural variables).

The model based on behavioural-attitudinal theory (

Figure 3) was found to be the most effective at modelling an information systems outsourcing relationship using questionnaire data obtained from 225 senior Korean information systems executives. It was developed using behavioural-attitudinal theory proposed by Kappelman and McLean (1991, 1992).

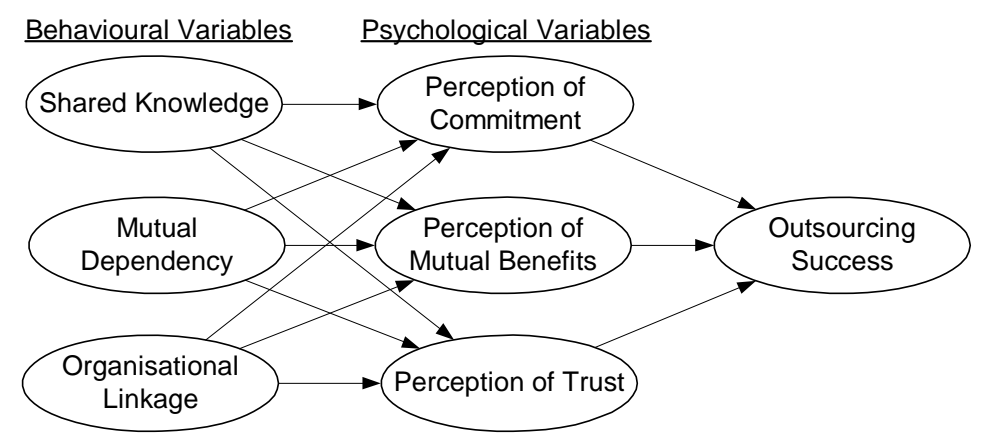

Figure 3 -Lee and Kim (2005) model based on Behavioural-Attitudinal theory

Kim and Chung (2003) and Kim and Park (2003) also developed cross-sectional single-dimensional information systems outsourcing relationship models. Kim and Chung (2003) proposed a model (

Figure 4) where the determinant factors were derived from relational exchange theory and transaction cost theory. They evaluated it using data obtained from a survey mailed to 2200 computer executives. Only solidarity, flexibility and monitoring of the vendor were found to be positively related to the success of information systems outsourcing. Surprisingly, they found that role integrity and asset specificity were negatively related to success.

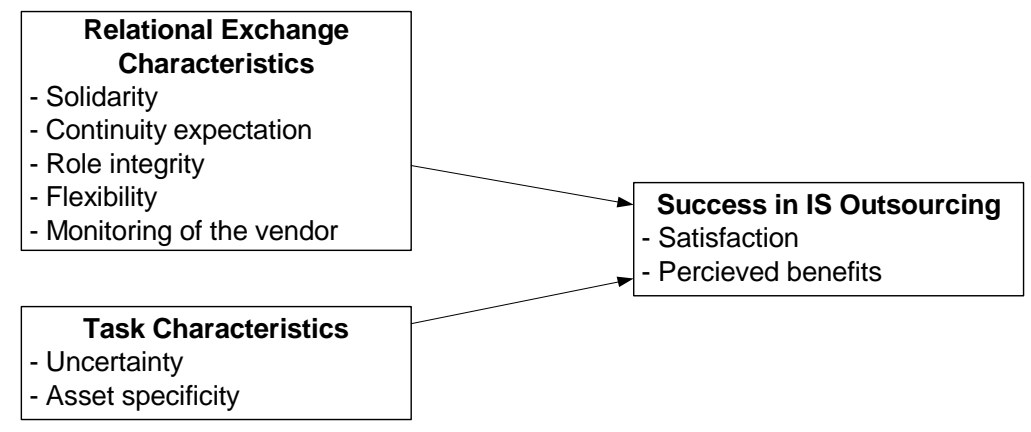

Figure 4 - Kim and Chung model (2003)

Kim and Park's (2003) model considered outsourcing satisfaction for three client groups within an information systems outsourcing relationship: outsourcing project director, users and operators 
(Figure 5). The project director is responsible for accepting the system provided by the vendor. The users are employees who use the information systems system while the operators are a customer group that represents the maintenance technologists within the client company. As expected, they found that the factors that influenced each of the groups within the client company differed. The project director's satisfaction was influenced by the transaction relationship and partnership constructs while output performance had a positive influence on the satisfaction of the users and operators, reflecting the fact that short-term consequences are important for these groups (Kim and Park, 2003).

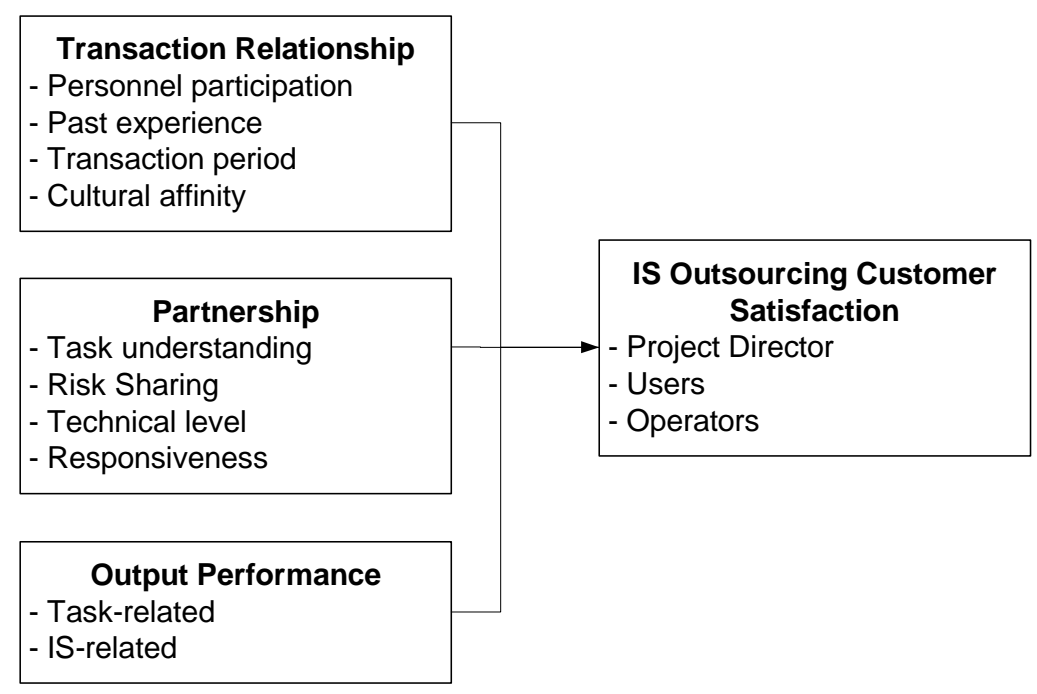

Figure 5 - Kim and Park (2003) model

\section{RESEARCH APPROACH}

This research aims to propose an improved outsourcing relationship model in an Australian context. To achieve this aim the following research approach has been adopted.

Step 1: Develop an extended relationship outsourcing model based on the literature discussed in the previous section.

Step 2: Perform a preliminary validation of the factors and structure of the extended outsourcing relationship model.

Step 3: Refine the extended model based on the results of the preliminary validation. 


\section{DEVELOPMENT OF EXTENDED MODEL}

In this section we discuss the development of the extended outsourcing relationship model and then consider how the constructs are measured.

Lee and Kim (2005) demonstrated that the model structure developed from behavioural-attitudinal theory, a model structure similar to the Lee and Kim (1999) model, to be the most effective structure to model an outsourcing relationship. As such it is used as the basis of the proposed information systems outsourcing relationship model (Figure 6). This structure has an intervening psychological dimension between the behavioural dimension and the overall outsourcing success of the relationship.

Two of the behavioural factors within the Lee and Kim (2005) model, shared knowledge and organisational linkage, proved to be effective positive determinants of the psychological dimension. Mutual dependency had a substantial negative influence on the psychological variables, but it is tested in the Australian context to determine whether their results "reflect Korea's unique outsourcing situation and environment" (Lee and Kim, 2005) or whether similar findings will occur in other countries.

The psychological dimension in Lee and Kim's (2005) study comprised perception of mutual benefits, perception of commitment and perception of trust (predisposition). These factors are included in the proposed model as they demonstrated a significant influence on outsourcing success.

The Lee and Kim (1999) model is similar in structure to the Lee and Kim (2005) behaviouralattitudinal model. However it includes additional factors to those tested in the later model: participation, communication quality, coordination, age of the relationship, cultural similarity, and top management support as behavioural factors; and business understanding and conflict as psychological factors. Of these factors, participation, coordination, communication quality and top management support are included in the behavioural dimension of the extended model as there was an influential relationship between these factors and the psychological dimension. Business understanding is included into the psychological dimension since it was found to have a positive relationship with outsourcing success. 


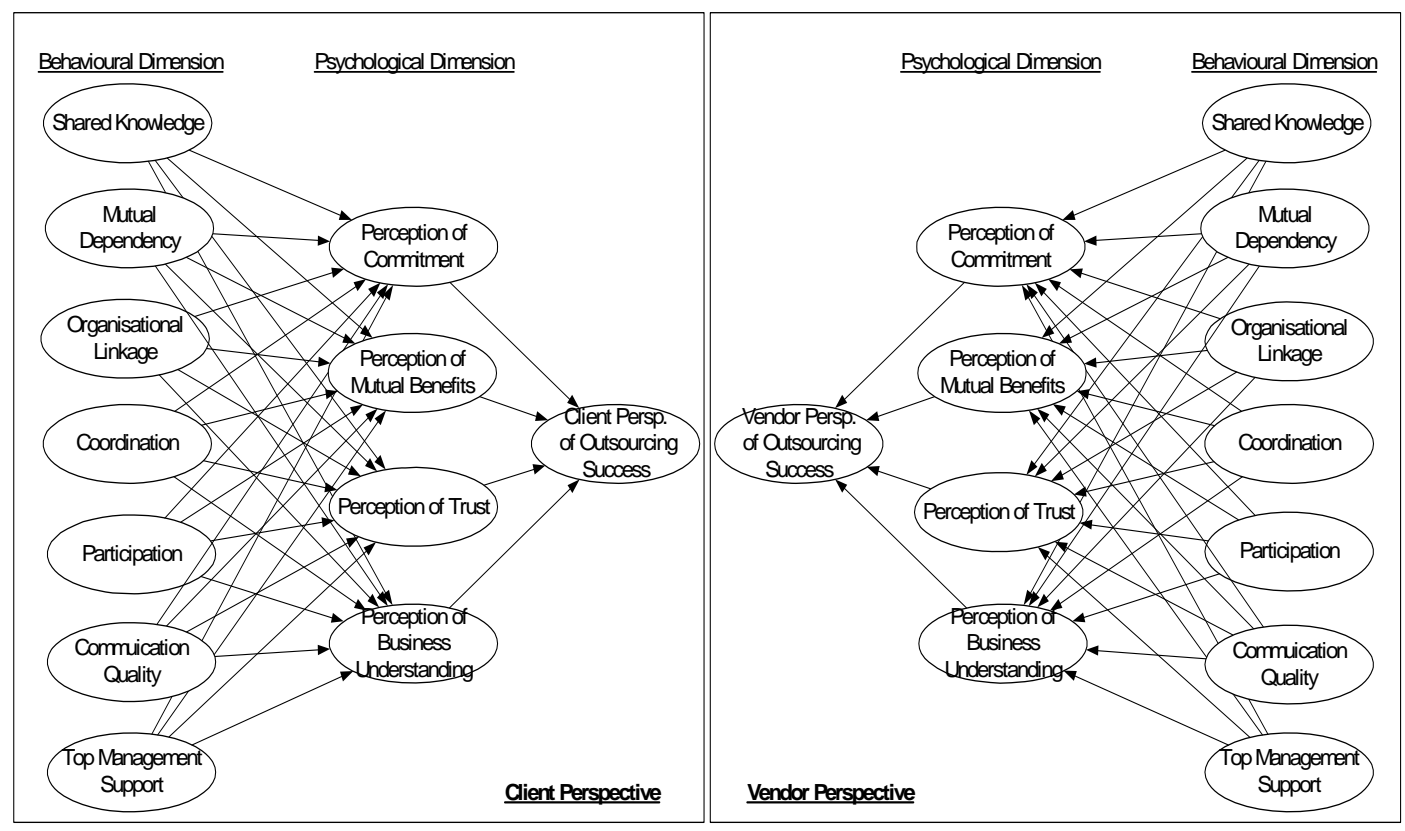

Figure 6 -Extended outsourcing relationship model

Kim and Park (2003) and Kim and Chung (2003) also developed models that endeavoured to determine the factors within an information systems outsourcing relationship. The majority of factors within these models overlapped with factors that have been extracted from the Lee and Kim (1999, , 2005) models. Of the factors that did not overlap, none were found to have a significant effect on outsourcing success and therefore were not included in the extended model.

Support for inclusion of the factors in the extended model is also found in the general outsourcing literature.

- $\quad$ Organisational linkage: (Henderson, 1990, Mohr and Spekman, 1994)

- Shared knowledge: (Henderson, 1990, Lacity and Hirschheim, 1993, Mohr and Spekman, 1994)

- Mutual dependency: (Henderson, 1990, Kern and Willcocks, 2000, Klepper, 1994, Lacity and Hirschheim, 1993, Mohr and Spekman, 1994)

- $\quad$ Participation: (Henderson, 1990, Kim and Park, 2003)

- Coordination: (Mohr and Spekman, 1994)

- Communication quality: (Mohr and Spekman, 1994)

- $\quad$ Top management support: (Henderson, 1990, Lee and Kim, 1997)

- Trust: (Henderson, 1990, Kern, 1997, Kern and Willcocks, 2000, Mohr and Spekman, 1994, Sabherwal, 1999)

- $\quad$ Business understanding: (Kim and Chung, 2003, Kim and Park, 2003) 
- Mutual benefits: (Ang and Straub, 1998, Henderson, 1990, Kim and Park, 2003, Koh et al., 1999, Koh et al., 2004, Mohr and Spekman, 1994)

- Commitment: (Kern, 1997, Kern and Willcocks, 2000, Kim and Chung, 2003, Mohr and Spekman, 1994)

\section{Constructs}

The proposed extended outsourcing relationship model (Figure 6) uses the constructs developed by Lee and Kim (1999, , 2005) for the behavioural and psychological factors. The behavioural factors are:

- Communication Quality - the timeliness, accuracy, completeness and credibility of communication. Lee and Kim (1999) regard effective communications as essential for the partners to reach their intended objectives since it assists them in being better informed.

- Coordination - how well the partners work together to understand each other's needs and solve complex tasks. Coordinated actions between partners are judged to lead to mutual benefits and successful partnerships.

- Mutual Dependency - the extent to which the partners can influence each other as well as the extent to which they depend on each other. It develops through both partners perceiving mutual benefits from their interaction (Lee and Kim, 2005).

- Organisational linkage - the level of cooperation and joint effort that exists between the partners. As organisational linkage increases, organisational boundaries become blurred with the integration of activities such as long-range planning, value analysis and training (Lee and Kim, 2005).

- $\quad$ Participation - the level of involvement of both partners in the outsourcing relationship. Active participation of the partnership members plays a major part in enhancing the longterm sustainability of the partnership (Henderson, 1990).

- Shared knowledge - the extent to which critical information is communicated between the partners. Closer relationships should result in more frequent and more relevant information exchanges (Lee and Kim, 2005, Lee et al., 2000).

- Top management support - how well executives from each partner understand and support the partnership.

The psychological dimension variables are:

- Perception of business understanding - the degree to which the partners understand and comprehend each other's goals, policies and behaviours.

- Perception of commitment - the degree of pledge of relationship continuity between the partners. The presence of commitment allows the partners to focus on the long-term benefits rather than short-term benefits. The contractual side of a relationship is an important influence on the relationship commitment of the partners, due to the reassurance that the contract provides. The contract is seen as the first step of commitment; after this stage, the partners become proactive beyond what the contract suggests (Lee and Kim, 2005, Henderson, 1990).

- Perception of mutual benefits - the degree to which each partner shares the risks and benefits as well as mutual incentives. This construct is only influential if the relationship is 
a partnership-based relationship rather than the transactional type where understanding mutual benefits is less significant (Lee and Kim, 2005).

- Perception of trust - the degree of confidence and willingness between the partners (Lee and Kim, 1999). A lack of trust can lead to the client being unwilling to delegate responsibility to the vendor (Sabherwal, 1999).

Within the majority of the information systems outsourcing literature, the client perspective is used to measure the outcome of an information systems outsourcing relationship. The client perspective of outsourcing success is broken down into three measures.

- Generic satisfaction (Grover et al., 1996, Heckman et al., 1994, Kim and Chung, 2003, Kim and Park, 2003, Lee and Kim, 1999, Lee and Kim, 2005, Poppo and Zenger, 1998).

- Realisation of client expectations (Lacity et al., 1996, Lacity and Hirschheim, 1993, Reponen, 1993).

- $\quad$ Overall performance of the outsourced system (Sabherwal, 1999).

Since the extended model is intended to apply to both the client and vendor perspectives of an outsourcing relationship, the generic satisfaction measure is the more applicable measure. Generic satisfaction may measure different aspects of satisfaction depending on the context: overall satisfaction, business satisfaction, and user satisfaction. The proposed research model employs each of these categories to determine the success of an outsourcing relationship from both a client and vendor perspective.

The overall satisfaction measure adopted is adapted from Poppo and Zenger's (1998) study that delineates the satisfaction measure into three basic measures of overall cost, quality of service and the responsiveness to problems and enquiries. The business satisfaction measure is derived from the Grover et al. (1996) study and has been used along with the user satisfaction to measure information systems outsourcing success in both the Lee and Kim (1999, , 2005) studies. They measured user satisfaction as: reliability, relevance, timeliness, accuracy, currency, and completeness of the information provided to the users in the outsourcing relationship.

\section{PRELIMINARY VALIDATION OF EXTENDED MODEL}

A case study of the outsourcing relationship between a client (Client $\mathrm{X}$ ) and vendor (Vendor A) was conducted. The relationship between the two parties is still relatively young with respect to the full length of the contract. However it is sufficiently developed for any initial relationship and contractual issues to be resolved.

Previous to this information systems outsourcing agreement, Vendor A has been involved in a smaller-scale outsourcing relationship with Client $\mathrm{X}$ which was not regarded by either side as successful. When Client $\mathrm{X}$ looked to outsource more of its information systems infrastructure, it renegotiated its current outsourced desktop infrastructure relationship to include its network and voice infrastructure as well as development. The renegotiated contract was consciously reestablished to be a more beneficial relationship for both parties.

As this is a preliminary validation aimed at providing support for the initial model and any possible modifications, we conducted a limited number of interviews. Three interviews were conducted with information systems outsourcing professionals from Client X (C1, C2 and C3) who had at least 3 years management experience with relationships from a client perspective and four interviews with 
information systems professionals from Vendor A (V1, V2, V3 and V4) who have at least 5 years experience with outsourcing relationships from a vendor perspective. Each interview lasted approximately an hour.

The first phase of the interview process followed an investigatory interview structure similar to that adopted by Henderson (1990).

- Determine the interviewee's experience within IS outsourcing relationships, including the number of years involved and the roles held.

- Obtain an understanding of the IS outsourcing relationships with which the interviewee had been involved (both with the current employer and elsewhere).

- Determine what factors (with examples) the interviewee believes affect the success of the current outsourcing relationship.

- Determine the factors of an outsourcing relationship that the interviewee believes contribute to the relationship's effective execution on a day-to-day basis?

- Determine the factors of an outsourcing relationship that lead the interviewee to believe that a relationship will be sustained over time?

The second phase of the interview considered the proposed extended outsourcing relationship model. The extended model was presented to each of the interviewees and he/she was asked to respond to the following questions.

- The perception of the overall model structure and relevance to how the interviewee believes an IS outsourcing relationship functions.

- The perception of each of the variables within the model and the validity of each of the variables as a determinant of IS outsourcing success.

- Discussion of the feedback effect (e.g. does a vendor's perception of a satisfied client influence a vendor's satisfaction.)

\section{INTERVIEW ANALYSIS AND RESULTS}

This section discusses the results of the interviews with both client and vendor information systems outsourcing professionals. Table 1 summarises the client and vendor perspectives of each of the factors. The client and vendor perspectives of an outsourcing relationship and the responsibilities that come with these perspectives are notably different. This differentiation leads to differences in the importance each partner places on the various factors.

In the first phase of the interviews, the interviewees discussed their experiences and views of what influences the outcome of an information systems relationship. The client interviewees found trust to be the most important factor with $\mathrm{C} 2$ commenting:

trust has to be the most important factor that will tend to ensure that the relationship will be last a long period of time. Trust doesn't exist between Client X and Vendor A; it exists between me and my counterparts at Vendor A. You can’t measure trust; you can't have a KPI on trust. You either trust someone or you don't and you can't put together a process that causes someone to trust you, it's just the way that you behave.

C3 had a similar impression: 
there can obviously be some major things that undermine the value of the relationship, trust is one of them but we try to differentiate between the individual and the organisation. You can deal with an individual trust problem... but if you have an organisation trust problem it can leave the relationship undermined.

The vendor interviewees also found trust to be the most essential factor. V2 conveyed the vendor's overall perspective:

at the end of the day Client $\mathrm{X}$ has to trust me to make the technical decisions, as that is what they has empowered me to do.

Communication quality is an important factor for both parties, but the client interviewees considered it more essential as the client had outsourced its systems and infrastructure and required clear communication as to their status. C2 indicated that "after trust the most important factor within a relationship is to communicate and set expectations realistically with your partner". He also recognised that the existence of "communication is an indication of 'one team' benefits."

The client was more influenced by mutual benefits than the vendor as the client placed greater emphasis on getting value for money for the systems and infrastructure it had outsourced. For instance C1 noted that the IS outsourcing relationship is "not a zero sum game - that every dollar that Vendor A gains is not a dollar that Client X loses.” C3 remarked that Client A's objective was to "work with Vendor A to see if we could solve things mutually, how they increase their revenue and we increase our services."

The vendor was less influenced by sharing mutual benefits as the contract already stipulates the vendor's desired benefit and income. V1 remarked that for mutual dependency to exist within an IS outsourcing relationship

the deal has to be fundamentally sound on both sides, if not both sides will be unsatisfied. The previous deal between Client X and Vendor A, had some commercial challenges that led to ongoing commercial issues through the life of that contract, which is the reason why we signed a new contract.

The vendor's requirement for the client's business knowledge was evident in the importance that the vendor interviewees placed on business understanding. V1 commented shared knowledge is critical to the overall success of the whole arrangement. We try to have an open book on all aspects of the engagement other than confidential commercial issues but basically anything that we know, we allow our customer to share that knowledge as well.

Obviously, the greater the vendor's business understanding the easier it is to provide a quality service to the client. It is not surprising that the vendor placed an equal emphasis on the shared knowledge behavioural factor. The vendor requires the client to share its strategic and business knowledge to enable it to develop the necessary business understanding. V4 commented "sharing developed understanding is an integral part of making sure that both parties are focused on the common goal"

The interviews were able to provide substantial information in regards to the structure, perspective and factors within the extended outsourcing relationship model presented to the interviewees.

The behaviour-attitudinal structure defined within the model is consistent with the interviewees' belief that a partner's perception of the relationship is more influential on the overall success of the relationship than a partner's behaviour in the relationship. For instance V2 said he: agreed with psychological dimension, as partners within a relationship [develop] a mental model of how things should happen. This is impacted by good experiences. 
There was unanimous agreement that a client perceives an outsourcing relationship differently to how a vendor perceives the same relationship. V4 concurred with other interviewees indicating that it would be

interesting to measure and compare the relationship from both perspectives as the vendor is primarily concerned about the requirements within the relationship, whereas the client is more interested with their expectations being met, only when these meet can a similar measurement be used.

The interviews found that all of the factors proposed in the model were applicable to both perspectives. Although the common consensus of the interviewees was that some of the factors may be more influential on one perspective and less influential on the other (see also Table 1). 


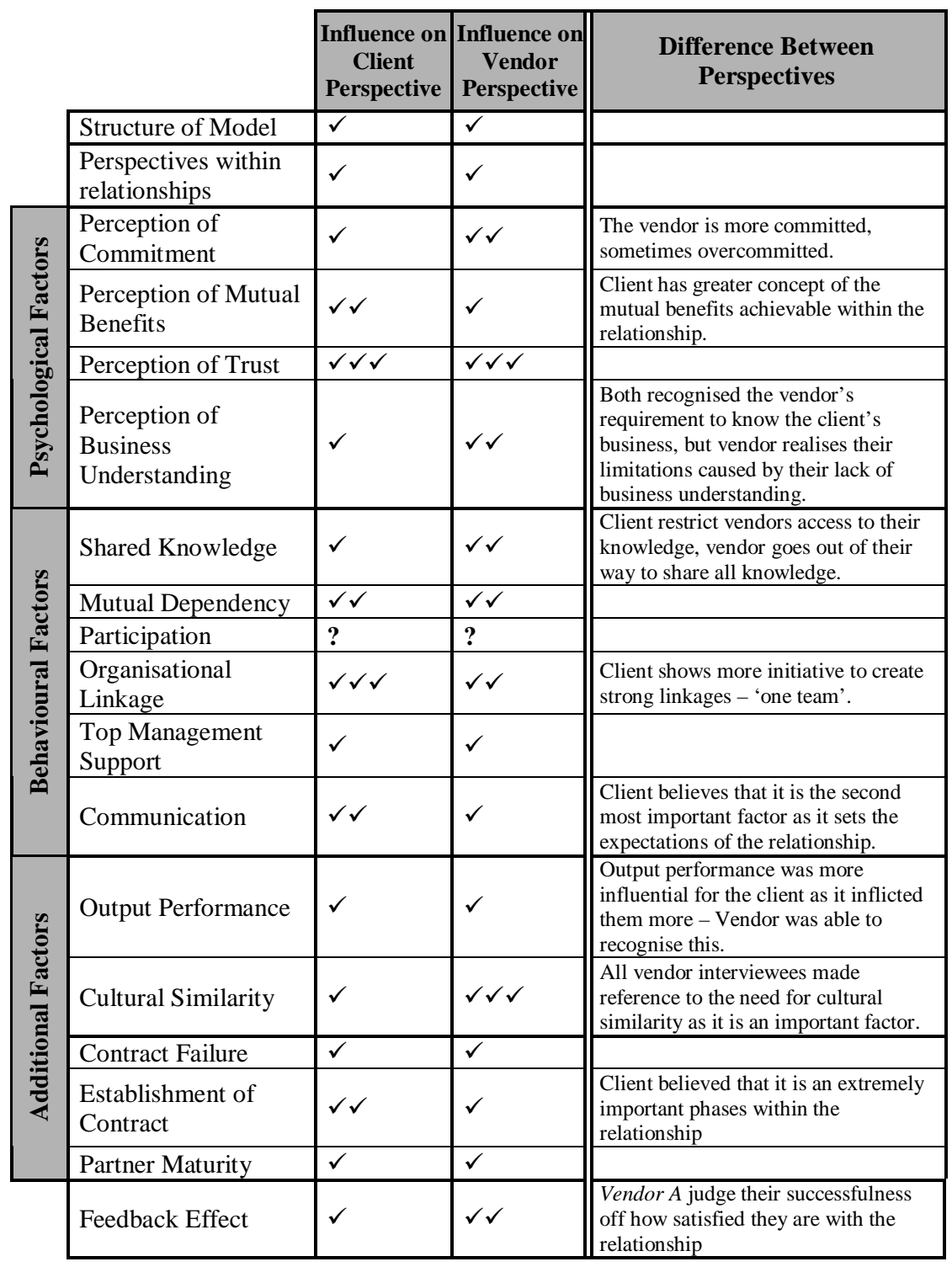

$\mathbf{x}=$ Rejected factor $\quad$ ? = Unverified factor $\checkmark=$ Validated factor

$$
\checkmark \checkmark=\text { Important factor } \quad \checkmark \checkmark \checkmark=\text { Essential factor }
$$

Table 1 - Comparison of how factors were perceived differently by the client and vendor perspectives

The interviewees also commented that users with different perspectives within the organisations will perceive the outsourcing relationship differently, signifying that they will be satisfied differently in an outsourcing relationship and that their satisfaction will be influenced by different factors. Kim and Park (2003) also found differences in the effect that some factors had on outsourcing customer satisfaction for each of the three client groups studied: project director, user and operator. 
The interviews were able to confirm the model from both the client and vendor perspectives. The factors within the model were considered appropriate although, interestingly, none of the interviewees directly indicated whether participation was a decisive factor in the model. The requirement for participation was indirectly ascertained from the interviewees' behaviour and extraneous comments.

\section{MODIFICATION TO THE EXTENDED MODEL}

Although the interviewees confirmed the structure and factors included in the model, they also discussed other factors that they also deemed important in an outsourcing relationship: cultural similarity, output performance, outsourcing experience, perception of partner satisfaction (feedback effect), and contract establishment. The first four factors are included in the revised model (Figure 7). Contract establishment is not included as its effects should be accommodated by the factors already included within the behavioural and psychological dimensions of the model.

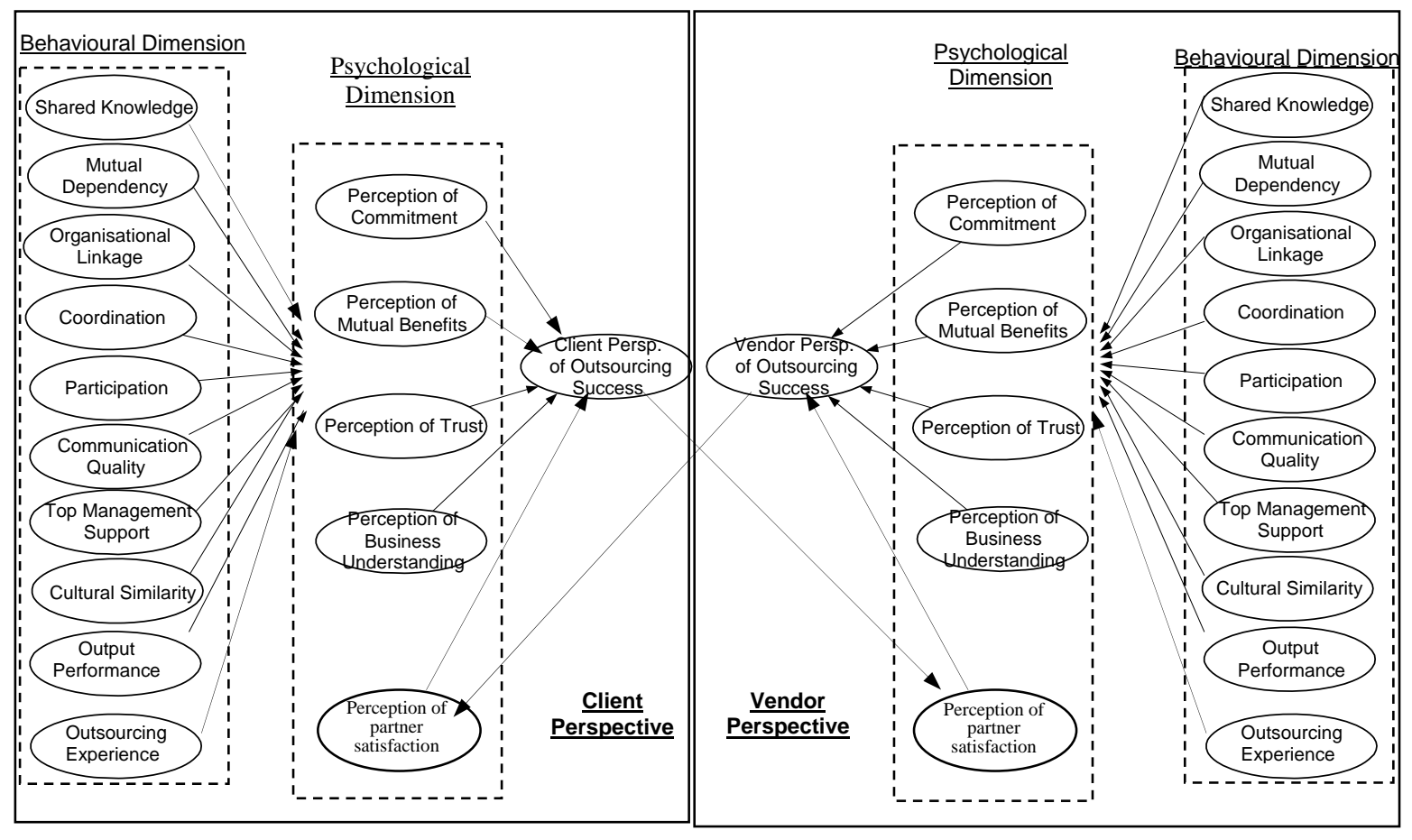

Figure 7- Revised extended outsourcing relationship model

\section{CULTURAL SIMILARITY}

Both partners noted the omission of cultural similarity and highlighted the influence that similar organisational cultures have on organisations being able to establish a strong relationship. For 
instance V3 commented “cultural similarity plays an important role within the relationship as both partners' culture allow for an easier relationship to develop."

Although cultural similarity was not shown to be an influencing factor within the Lee and Kim (1999) and Kim and Park (2003) models, the interviews suggest it should be included in the revised extended model.

\section{Output Performance}

Output performance was not originally included in the model as it had a mixed influence on different groups in the Kim and Park study (2003). The factor had a negative influence on the project director's satisfaction levels and a positive influence on the users' and operators' satisfaction levels.

However V3 commented that "part of keeping Client X happy is to deliver satisfactory services and meet our agreements with them." The influence of performance was also evident from a client perspective with C3 stating that there was a "remarkable improvement in quality and timeliness of delivered systems from Vendor A over the last two years."

Output performance is an influential factor in regards to determining how an outsourcing relationship is perceived. For this reason output performance is included in the model as a factor within the behavioural dimension.

\section{Outsourcing experience}

The interviewees believed that "the customer's lack of experience causes problems with the outsourcing relationship." Client X and Vendor A are both rather immature in regards to their outsourcing experience and find that this immaturity can act as a hindrance to the relationship. However C2 commented: "Vendor A's naivety and lack of experience made it easier for me to manage the outsourcing relationship."

There is a parallel between outsourcing experience and age of relationship which was unsuccessfully tested as a behavioural factor within the Lee and Kim (1999) model. The factor was employed to represent the belief that longer relationships are more likely to continue than short-term and younger relationships, as the longer timeframe would have allowed the partners to develop the relationship over time.

\section{Contract Establishment}

The importance of the method used to establish an outsourcing contract was a point that was touched on by many of the interviewees, in particular from the client perspective. They commented that the bid stage was often conducted in a highly confrontational manner. When it is conducted in such a way, it creates a problem when the relationship has to start once the contract been signed. The relationship has not had time to recover from the confrontational bid.

The other problem with the contract negotiation stage is that the contract sets the direction for the relationship. If the contract is insufficient in explaining what the client needs or what the vendor can supply, it leads to problems that need to be solved by the newly established relationship. 


\section{The Feedback Effect}

There was an overall agreement that a feedback effect is an existent part of an outsourcing relationship. C2 commented on the feedback effect being existent from the client perspective as "keeping the vendor happy is just as important as keeping the client happy." He then went on to say that "a good relationship leads to a good account to work on, which leads to the best employees to work on it. It is in our interests to be a good customer."

However the vendor respondents generally recognised the feedback effect to a greater extent than the client respondents with V1 commenting

it's (feedback) a real effect; if I think that they are happy, I make my team happy, the customer sees a happier team, their team is happier. If there is a major level of dissatisfaction across the customer environment that impacts all levels of the relationship and our internal perception of that does alter the attitudes and behaviours within my organisation.

The interviews have shown that the feedback effect is existent in outsourcing relationships. This factor is included as a psychological factor, perception of partner satisfaction, in the revised model.

\section{CONCLUSION}

The overall objective of this research was to provide an improved understanding of the factors affecting the success of an outsourcing agreement. The proposed model was based on previous models described in the literature. Interviews with outsourcing professionals associated with one client/vendor outsourcing relationship were conducted. The interviews found a considerable difference between the factors that a client recognises to be essential and the factors that a vendor believes are important. Agreement was achieved on the structure of the proposed model along with its factors. However four additional factors were identified and are included in the revised extended model (Figure 7): cultural similarity, output performance, outsourcing experience, and perceived partner satisfaction (feedback effect).

The current research is useful to management in that it provides an improved understanding of the factors that affect outsourcing success in a major Australian outsourcing relationship. It also highlights the importance of the feedback effect with the vendor respondents generally recognising its importance to a greater extent than the client respondents.

The validation is limited to a single outsourcing relationship between two organisations. Although it supports the factors and the form of the proposed model, it is also limited since it is based on qualitative information from the one outsourcing relationship. To better determine the structural fit of the proposed model and improve its generalisability a quantitative study using questionnaire data across a number of outsourcing relationships is planned. This will be analysed using PLS (Chin, 1998).

\section{REFERENCES}

Ang, S. \& Straub, D. W. (1998) "Production and Transaction Economies and IS Outsourcing: A Study of the U.S. Banking Industry", MIS Quarterly, Vol 22 No 4: pp 535-552. 
Chin, W. W. (1998) "(1) Issues and Opinion on Structural Equation Modeling", MIS Quarterly, Vol 22 No 1 (March): pp vii-xvi.

Dibbern, J., T. Goles, R. Hirschheim, B. Jayatilaka (2004) "Information Systems Outsourcing: A Survey and Analysis of the Literature", Database for Advances in Information Systems, Vol 35 No 4: pp 6-102.

Fitzgerald, G. \& Willcocks, L. P. (1994) Contracts and Partnerships in The Outsourcing of IT. Fifteenth International Conference on Information Systems, Vancouver: Canada.

Grover, V., Cheon, M. J. \& Teng, J. T. C. (1996) "The Effect of Service Quality and Partnership on the Outsourcing of Information Systems Functions", Journal of Management Information Systems: JMIS, Vol 12 No 4 (Spring): pp 89-116.

Heckman, R., King, W. R. \& Beachboard, J. (1994) Behavioral Consequences of Customer Satisfaction with Outsourcing Services: Discretionary Collaboration, Relationship Commitment, and Coflict. Fifteenth International Conference on Information Systems, Vancouver.

Henderson, J. C. (1990) "Plugging into Strategic Partnerships: The Critical IS Connection", Sloan Management Review, Vol 3 No: pp 7-18.

Kappelman, L. \& Mclean, E. (1991) The Respective Roles of User Participation and User Involvement in Information System Implementation Success. Proceedings of the 12th International Conference on Information Systems.

Kappelman, L. A. \& Mclean, E. R. (1992) "Promoting Information System Success: The Respective Roles of User Participation and User Involvement", Journal of Information Technology Management, Vol 3 No 1: pp 1-12.

Kern, T. (1997) The Gestalt of an Information Technology Outsourcing Relationships: An Explanatory Analysis. Eighteenth International Conference on Information Systems.

Kern, T. \& Willcocks, L. P. (2000) "Exploring Information Technology Outsourcing Relationships: Theory and Practice", Journal of Strategic Information Systems, Vol 9 No: pp 321-350.

Kim, B. \& Park, K. (2003) "Satisfying different customer groups for IS outsourcing: a Korean IS company's experience", Asia Pacific Journal of Marketing and Logistics, Vol 15 No 3: pp 48-69.

Kim, S. \& Chung, Y. S. (2003) "Critical success factors for IS outsourcing implementation form an interorganisational relationship perspective", Journal of Computer Information Systems, Vol 43 No 4: pp 81-90.

Kishore, R., Roa, H., Nam, K., Rajagopalan, S. \& Chandhury, A. (2003) "A Relationship Perspective on IT Outsourcing", Communications of the ACM, Vol 46 No 12: pp 86-92.

Klepper, R. (1994) "Outsourcing Relationships", in KHOSROWPOUR, M. (ed.) Managing Information Technology Investments with Outsourcing. Harrisburg, PA: Idea Group Publishing, 218-243 p.

Koh, C., Ang, S. \& Straub, D. W. (2004) "IT Outsourcing Success: A Psychological Contract Perspective", Information Systems Research Vol 15 No 4: pp 356-373.

Koh, C., Tay, C. \& Ang, S. (1999) Managing Vendor-Client Expectations in IT Outsourcing: A Psychological Contract Perspective. 20th International Conference on Information Systems. 
Lacity, M. C. \& Hirschheim, R. (1993) Information Systems Outsourcing: Myths, Metaphors, and Reality, New York: John Wiley and Sons.

Lacity, M. C., Willcocks, L. P. \& Feeny, D. F. (1996) "The Value of Selective IT Sourcing", Sloan Managment Review, Vol 37 No 3: pp 13-25.

Lee, J.-N., Huynh, M. Q., Chi-Wai, K. R. \& Pi, S.-M. (2000) The Evolution of Outsourcing Research: What is the Next Issue? 33rd Hawaii International Conference on Systems Sciences.

Lee, J.-N. \& Kim, Y.-G. (1997) "Information Systems Outsourcing Strategies for Affiliated firms of the Korean Conglomerate Groups", Journal of Strategic Information Systems, Vol 6 No 3: pp 203-229.

Lee, J.-N. \& Kim, Y.-G. (1999) "Effect of partnership Quality on IS Outsourcing Success: Conceptual Framework and Empirical Validation." Journal of Management Information Systems, Vol 15 No 4: pp 29-61.

Lee, J. N. (2005) Explanation of differences between 1999 model and 2005 model. IN FLEMING, R. (Ed.) Sydney.

Lee, J. N. \& Kim, Y. G. (2005) "Understanding Outsourcing Partnership: A Comparison of Three Theoretical Perspectives", IEEE Transactions on Engineering Management, Vol 52 No 1: pp 43-58.

Mcfarlan, F. W. \& Nolan, R. L. (1995) "How to manage an IT outsourcing alliance", Sloan Management Review, Vol No Winter: pp 9-23.

Mohr, J. \& Spekman, R. (1994) "Characteristics of partnership success: Partnership attributes, communication, behavior, and conflict resolution techniques", Strategic Management Journal, Vol 15 No: pp 135-152.

Poppo, L. \& Zenger, T. (1998) "Testing Alternative Theories of the Firm: Transaction Cost, Knowledge- Based, and Measurement Explanations for Make-or- Buy Decisions in Information Services", Strategic Management Journal, Vol 19 No: pp 853-877.

Reponen, T. (1993) Outsourcing or Insourcing. The 14th International Conference on Information Systems.

Sabherwal, R. (1999) "The Role of Trust in Outsourced IS Development Projects", Communications of ACM, Vol Vol. 42 No No.2: pp 80-86. 